\title{
Adsorption of Zinc from Aqueous Solutions Using Modified Brazilian Gray Clay
}

\author{
Patrícia N. M. Vasconcelos ${ }^{1}$, Wellington S. Lima ${ }^{1}$, Marta L. P. Silva ${ }^{2}$, André L. F. Brito ${ }^{1}$, \\ Hervé M. Laborde ${ }^{1}$, Meiry G. F. Rodrigues ${ }^{1}$ \\ ${ }^{1}$ Federal University of Campina Grande, Academic Unit of Chemical Engineering, Campina Grande, Brasil \\ ${ }^{2}$ Rural Federal University of Semi Arid, Agrotechnology and Social Science Departamento, Mossoró, Brasil \\ Email: noemiacelos@yahoo.com.br,ws1_20@yahoo.com.br, \\ andre@deq.ufcg.edu.br, herve@deq.ufcg.edu.br, meiry@deq.ufcg.edu.br
}

Received May 21, 2013; revised June 22, 2013; accepted July 15, 2013

Copyright (C) 2013 Patrícia N. M. Vasconcelos et al. This is an open access article distributed under the Creative Commons Attribution License, which permits unrestricted use, distribution, and reproduction in any medium, provided the original work is properly cited.

\begin{abstract}
In this study, the removal of zinc $\left(\mathrm{Zn}^{2+}\right)$ from aqueous solutions was investigated using a Na-enriched Brazilian gray clay. The mineral clays were characterized through EDX, XRD analysis and CEC. A finite bath system was used to evaluate the main effects of mechanical agitation (from 100 to $200 \mathrm{rpm}$ ), $\mathrm{pH}$ values in the range from 6.0 to 8.0 and $\mathrm{Zn}^{2+}$ initial concentrations (from 10 to $50 \mathrm{mg} / \mathrm{L}$ ) on the removal process capacity. Langmuir and Freundlich isotherm models were applied in order to determine the efficiency of clay used as an adsorbent. According to the obtained results, Langmuir model adjusts very well to the experimental data. Based on the kinetic studies for the Na-enriched gray clay, it was verified that the mechanism corresponds to a predominant pseudo-second order adsorption, presenting a kinetic constant value equal to $\mathrm{k}=1.13(\mathrm{~g} \cdot \mathrm{min} / \mathrm{mg})$.
\end{abstract}

Keywords: Adsorption; Gray Mineral Clays; Zinc; Separation of Heavy Metal

\section{Introduction}

The presence of heavy metals in the environment is detrimental to a huge variety of living organisms. Industrial effluents generated from industrial activities such as mining, metal coating and battery production [1] may contain several toxic heavy metals [2]. Because of its low biodegradability, heavy metals can present high environmental accumulation characteristics. The hazardous effect for living organisms is more pronounced when specific limits are exceeded [1].

Therefore, it is important to eliminate heavy metals from water and effluents in order to protect public health. Many methods have been proposed for removing heavy metals, and among them chemical precipitation, membrane filtration, ion exchange and adsorption are the most commonly used processes [3].

It is well-know that adsorption separation process has received considerable attention due to its high capacity in the removal of heavy metals. Although the large number of adsorbents used in adsorption methods, active carbon is the one that has been most commonly used for effluents treatment purposes all over the world [4]. In spite of that high cost associated with the treatment processes restricts the use of active carbon [5]. For this reason, many studies have been carried out in order to discover effective and low cost adsorbents. Different adsorbents can be used for removing copper and zinc, such as chitosan [6] and for treatment of agricultural wastes, such as wheat shell [7] and cacao shell [8].

Natural clay is considered an appropriate adsorbent due to its low cost and high removal efficiency. In addition, important features such as large specific area, Bronsted and Lewis acidity, chemical and mechanical stability, layered structure and high capacity cation exchange [9] can make the mineral clays useful materials intended to be used as adsorbents. The Brönsted acidity arises from $\mathrm{H}^{+}$ions on the surface, formed by dissociation of water molecules of hydrated exchangeable metal cations on the surface. The Brönsted acidity may also arise if there is a net negative charge on the surface due to the substitution of $\mathrm{Si}^{4+}$ by $\mathrm{Al}^{3+}$ in some of the tetrahedral positions and the resultant charge is balanced by $\mathrm{H}_{3} \mathrm{O}^{+}$cations. The Lewis acidity arises from exposed trivalent cations, mostly $\mathrm{Al}^{3+}$ at the edges, or $\mathrm{Al}^{3+}$ arising from rupture of 
Si-O-Al bonds, or through dehydroxilation of some Brönsted acid sites [9].

The edges and the faces of clay particles can adsorb anions, cations, non-ionic and polar contaminants from water. The contaminants accumulate on clay surface leading to their immobilization through the process of ionexchange, coordination, or ion-dipole interactions. Sometimes the pollutants can be held through H-bonding, Van der Waals interactions or hydrophobic bonding arising from either strong or weak interactions [33]. The strength of the interactions is often determined by structural features of the mineral clay.

According to Van Olphen [10], several types of active sites can be found in clays: 1) Brönsted acid or proton donor sites, created by interactions of adsorbed or interlayer water molecules; 2) Lewis acid or electron acceptor sites occurring due to dehydroxilation; 3) oxidizing sites, due to the presence of some cations (e.g. $\mathrm{Fe}^{3+}$ ) in octahedral positions or due to adsorbed oxygen on surfaces; 4) reducing sites produced due to the presence of some cations (e.g. $\mathrm{Fe}^{2+}$ ); and 5) Surface hydroxyl groups, mostly found in the edges, bound to $\mathrm{Si}, \mathrm{Al}$ or other octahedral cations [33].

It is widely known that there are three basic species of mineral clays: smectites (such as montmorillonite), kaolinite and micas, out of which montmorillonite has the highest cation exchange capacity, which sorption capabilities arise from the fact that mineral clays normally present high surface area and exchange capacity. The negative charge on the structure of mineral clays given is responsible for the ability clay to attract metal ions [11]. It is generally agreed that clay is an efficient adsorbent for some heavy metals, especially for lead [12], copper [13], cadmium [14], zinc [1,5,15,16] and nickel [17]. Although kaolinite exhibits the least exchangeability, some studies have confirmed the potential of natural and modified kaolinites for the adsorption of metal ions from solutions [16,18-24].

It is evident from the literature survey that inexpensive and locally available materials could be used instead of commercial activated carbon [2].

This work has the purpose of evaluating the removal of zinc on Na-enriched gray clay in finite bath experiments. The samples (untreated and treated) were characterized by X-ray energy dispersion spectrophotometer, X-Ray Diffraction and Cation Exchange Capacity. Adsorption assays were conducted according to a $2^{3}$ factorial design with three central points to evaluate the main effect of process variables, such as, initial metal concentration $(\mathrm{Zn})$ in aqueous solution $\left(\mathrm{C}_{0}\right), \mathrm{pH}$ and mechanical agitation. The system responses to the variation of the process variable were determined based on measurements of the: total metal $(\mathrm{Zn})$ removal percentage (Rem $(\%))$ and removal capacity zinc at equilibrium $\left(q_{e q}\right)$. Both the adsorption isotherm and the kinetic mechanism of adsorption were studied, and Langmuir and Freundlich models were utilized for analysis of the adsorption equilibrium data.

\section{Materials and Methods}

\subsection{Material}

This natural gray clay was kindly supplied by Süd-Chemie do Brasil Ltd and was sieved according to the Brazilian ABNT standard No $200(0.074 \mathrm{~mm})$ sieve.

Zinc(II) nitrate (VETEC) was used as a source for the $\mathrm{Zn}^{2+}$ metal ion. Diluted nitric acid and sodium hydroxide (Merck) solutions were used for $\mathrm{pH}$ adjustment. Deionized water was used in all experimental work.

\subsection{Treatment and Preparation of Gray Mineral Clay}

To obtain the clay in its sodium form, treatment with sodium chloride (2 M) were performed as follow: $1 \mathrm{mg}$ of clay was dispersed $25 \mathrm{~mL}$ of $\mathrm{NaCl}$ solution for 24 hours. Then, a new solution is used for another 24 hours. This treatment was carried out in a 2 L Becker flask with agitation, at room temperature. After filtration, the clay was dried for 72 hours at $60^{\circ} \mathrm{C}$. Finally the clay was triturated and classified by using a 200 mesh (ABNT-Brazilian Association of Technical Norms) sieve before being used in the zinc removal process. This procedure is necessary to reduce the attractive interaction between the layers of the clay, thus allowing for better penetration of water into the clay.

\subsection{Characterization of the Samples}

X-ray energy dispersion spectrophotometer (EDX): The elements present in the clays were determined through energy dispersive X-Ray spectrophotometer (EDX-700 Shimadzu).

X-Ray Diffraction (XRD): the XRD patterns of the samples were obtained by using Shimadzu XRD 6000 equipment, operating with Copper $\mathrm{K} \alpha$ radiation at 40 $\mathrm{KV} / 30 \mathrm{~mA}$, with a goniometer velocity of $2^{\circ} / \mathrm{min}$ and a step of $0.02^{\circ}$ in the range of $2 \theta$ scanning from $2^{\circ}$ to $45^{\circ}$.

Cation Exchange Capacity (CEC): The cation exchange capacity (CEC) was determined with the Marconi nitrogen distiller, model MA-036Plus. Initially, 5.0 grams of a sample, weighed on an analytical balance, were transferred to an Erlenmeyer flask containing $200 \mathrm{~mL}$ of a 3-M ammonium acetate solution; then the flask with the solution was put on a magnetic stirrer and left under constant agitation for 12 hours. After this period it was centrifuged and collection of only the sample was performed, which was washed with ethanol to remove excess ammonium acetate and centrifuged again. The col- 
lected material was transferred to a watch glass and remained at room temperature at $60^{\circ} \mathrm{C} \pm 5^{\circ} \mathrm{C}$ for 24 hours for drying. After drying, 1.5 gram of material was weighed on an analytical balance. The material was then manually disaggregated in a mortar and transferred to a Kjeldahl flask, to which $50 \mathrm{~mL}$ of distilled water and 3 drops of phenolphthalein were added and engaged in the apparatus. Sodium hydroxide (solution $50 \% \mathrm{w} / \mathrm{v}$ ) was added to the solution in the Kjeldahl flask until it became pink. Afterwards, vapor was injected into the reaction flask, causing a release of ammonia. The loose $\mathrm{NH}_{3}$ was passed through a distiller, and was then collected in a flask containing $50 \mathrm{~mL}$ of $4 \%$ boric acid with mixed indicator (methyl red and $0.50 \%$ bromocresol green in 0.75 $\%$ ethanol). The distillation time was about 10 minutes. The boric acid indicator at first showed a red color, then became green when it received $\mathrm{NH}_{3}$. After distillation, the material was withdrawn from the Erlenmeyer flask and the system proceeded to titration with 0.1-M hydrochloric acid until the color became red. The volume (in $\mathrm{mL}$ ) used for titration was then recorded. The Cation Exchange Capacity (CEC) is obtained with Equation (1).

$$
C E C=\frac{M \times f \times V_{H C l} \times 100}{M}
$$

where CEC is the Cation Exchange Capacity, M corresponds to the molar concentration of $\mathrm{HCl}=0.1(\mathrm{M}), \mathrm{f}$ is a conversion factor of the acid $=1, \mathrm{~V}_{\mathrm{HCl}}$ is the volume of $\mathrm{HCl}$ used for titration, expressed in $\mathrm{mL}, \mathrm{M}$ mass of sample, in $\mathrm{g}$.

\subsection{Factorial Experimental Design}

A factorial design was proposed with three factors aiming to analyze the influence of initial metal concentration $(\mathrm{Zn})$ in aqueous solution $\left(\mathrm{C}_{0}\right)$ on zinc adsorption process on Na-enriched gray clay. The variables obtained from this study were: the total metal $(\mathrm{Zn})$ removal percentage (Rem $(\%))$ and removal capacity zinc at equilibrium $\left(q_{e q}\right)$.

The values for levels (+) and (-) are shown in Table 1.

The experiments were performed in a finite bath experiments (batch reactor) with mechanical agitation and at room temperature. The $\mathrm{pH}$ is controlled by adding diluted $\mathrm{HNO}_{3}$ and/or $\mathrm{NaOH}$ solutions. The other variables were maintained constant and their values were selected from the literature (retention time $=5 \mathrm{~h}$; solution volume $=50 \mathrm{ml}$; clay mass $=0.5 \mathrm{~g}$ ) [36].

\subsection{Finite Bath System}

The experiments were performed simultaneously, and the matrix of experiments was followed closely. $0.5 \mathrm{~g}$ clay was weighed and put in contact with a $50 \mathrm{ml}$ solution with $\left(\mathrm{Zn}\left(\mathrm{NO}_{3}\right)_{2} \cdot 6 \mathrm{H}_{2} \mathrm{O}\right)$ with concentrations of 10,30 and $50 \mathrm{mg} / \mathrm{L}$. When the solution and clay were put in contact,
Table 1. Chemical analysis of the natural and Na-enriched clays.

\begin{tabular}{ccc}
\hline \multirow{2}{*}{ Composition (\%) } & \multicolumn{2}{c}{ Clay } \\
\cline { 2 - 3 } & Natural clay & Na-enriched clay \\
\hline $\mathrm{SiO}_{2}$ & 51.63 & 44.61 \\
$\mathrm{Al}_{2} \mathrm{O}_{3}$ & 23.61 & 21.32 \\
$\mathrm{Fe}_{2} \mathrm{O}_{3}$ & 9.29 & 9.16 \\
$\mathrm{MgO}$ & 3.04 & 3.09 \\
$\mathrm{CaO}$ & 3.71 & 0.69 \\
$\mathrm{~K}_{2} \mathrm{O}$ & 3.92 & 3.48 \\
$\mathrm{Na}_{2} \mathrm{O}$ & --- & 5.03 \\
$\mathrm{LOI}$ & 4.8 & 12.62 \\
\hline
\end{tabular}

the $\mathrm{pH}$ adjusted quickly to $6.0,7.0$ or 8.0 and was placed under mechanical agitation of 100,150 or $200 \mathrm{rpm}$ for 5 hours to ensure the balance of the system, during which the variation of $\mathrm{pH}$ was observed every $60 \mathrm{~min}$, and adjustments made (when necessary). After five hours, the solutions were filtered, after which the filtrate was analyzed through Atomic Absorption Spectrometry (Perkin Elmer AA Analyst 200).

\subsection{Determination of the Amount of Zinc Ions}

The total metal $(\mathrm{Zn})$ removal percentage (Rem (\%)) as well as the removal capacity zinc at equilibrium $\left(q_{e q}\right)$ can be obtained through Equations 2 and 3, respectively:

$$
\% \operatorname{Rem}=\left(\frac{C_{0}-C_{e q}}{C_{0}}\right) \times 100
$$

where \%Rem is the total metal $(\mathrm{Zn})$ removal percentage, $\mathrm{C}_{0}$ the initial concentration (ppm), and $C_{e q}$ the final concentration $(\mathrm{mg} / \mathrm{L})$.

A relatively simple equation can be used to obtain the amount of adsorbed zinc, expressed in $\mathrm{mg}$ of aqueous solution per gram of adsorbent solid, given as follows:

$$
q_{e q}=\frac{V}{m}\left(C_{0}-C_{e q}\right)
$$

where $q_{e q}$ is the removal capacity zinc at equilibrium (mg of zinc/g of adsorbent), $\mathrm{C}_{0}$ the initial concentration of zinc ion $(\mathrm{mg} / \mathrm{L}), C_{e q}$ the final concentration of zinc ion $(\mathrm{mg} / \mathrm{L}), \mathrm{V}$ the volume of the adsorbate $(\mathrm{mL})$, and $\mathrm{m}$ the mass of adsorbent $(\mathrm{g})$.

\subsection{Adsorption Isotherms}

The experiments were carried out simultaneously by placing five $125 \mathrm{ml}$ Erlenmeyer flasks containing $50 \mathrm{ml}$ zinc nitrate solution with concentrations of $10 \mathrm{mg} / \mathrm{L}, 30$ $\mathrm{mg} / \mathrm{L}, 50 \mathrm{mg} / \mathrm{L}, 70 \mathrm{mg} / \mathrm{L}$ and $100 \mathrm{mg} / \mathrm{L}$, respectively, in contact with $0.5 \mathrm{~g}$ clay and keeping them under agitation of $100 \mathrm{rpm}$ and $\mathrm{pH}$ controlled at 8 at a temperature of 27 ${ }^{\circ} \mathrm{C}$ for 5 hours to ensure the equilibrium of the system. 
The $\mathrm{pH}$ and agitation conditions were defined using the results obtained from the planning stage of the experiment. To control the $\mathrm{pH}$, whenever necessary, $0.1 \mathrm{M}$ hydrochloric acid and/or sodium hydroxide was added. When the predetermined experimental time was achieved, the solutions were filtered, after which the filtrate was analyzed by Atomic Absorption Spectrometry (Perkin Elmer AA Analyst 200).

\subsection{Adsorption Kinetics}

Kinetic studies for removing zinc were performed by using different concentrations $(10 \mathrm{mg} / \mathrm{L}, 30 \mathrm{mg} / \mathrm{L}, 50$ $\mathrm{mg} / \mathrm{L}, 70 \mathrm{mg} / \mathrm{L}$ and $100 \mathrm{mg} / \mathrm{L}$ ). Optimum conditions determined by the factorial experimental design results were used during the experiments. $\mathrm{pH}$ was adjusted to 8 and clay mass was $0.5 \mathrm{~g}$.

The kinetic test was performed using a finite bath system, in which the $\mathrm{pH}$, agitation and concentration conditions were determined by the finite bath test that provided the best percentage of removal of zinc by this clay.

The experiment consisted of keeping two $1000 \mathrm{~mL}$ beakers of a mixture at a ratio of 1/100 clay mass/volume of zinc nitrate solution, under constant agitation, at room temperature.

In order to study the kinetics of removal, solution aliquots $(4 \mathrm{~mL})$ were collected at time intervals of $0.5 ; 1$; $1.30 ; 2 ; 5 ; 8 ; 12 ; 16 ; 20 ; 30 ; 40 ; 60 ; 80 ; 100 ; 120 ; 140$; 160 and 180 minutes, to obtain the zinc concentration curve as a function of the removal time, in order to evaluate the equilibrium time. A special care has been taken that the volume removed would not exceed $8 \%$ of the total volume.

After specific time intervals, the solution aliquots were withdrawn and filtered, after which the filtrate was evaluated by means of Atomic Absorption Spectrometry (Perkin Elmer AA Analyst 200) measurements.

\section{Results and Discussion}

\subsection{Adsorbent Characterization}

The chemical composition of the compounds (natural gray clay and Na-enriched gray clay) is shown in Table 2. The observed values for the average composition of the clays agree very well with that one found in the open literature [25]. When the experimental data of natural gray and Na-enriched gray clays are compared, it can be observed that treatment with $\mathrm{NaCl}$ was successfully accomplished, as $\mathrm{Na}_{2} \mathrm{O}$ is observed with molar composition equal to $5 \%$. It's important to emphasize that lixiviation of other oxides were not noticed, as for example $\mathrm{Al}_{2} \mathrm{O}_{3}$, $\mathrm{Fe}_{2} \mathrm{O}_{3}, \mathrm{MgO}$ and $\mathrm{K}_{2} \mathrm{O}$, whose average composition values are kept very similar in both mineral clays.

The quantitative CEC value obtained for natural gray clay is of approximately $84 \mathrm{meq} / 100 \mathrm{~g}$. Clay minerals generally have CEC values between 3 and 150 meq/100 g [25]. The comparatively high CEC value of natural clay indicates that the minerals have a high level of isomorphic substitutions [25].

The results of the X-Ray diffraction of the samples of natural gray clay and Na-enriched gray clay are presented in Figure 1. The crystallographic pattern obtained for the natural gray clay is characterized by peaks of mica with reflections at $10.08 \AA$ and peaks of kaolinite with reflections at $7.17 \AA$. The XRD pattern of this sample also shows a $7.59 \AA$ peak, which may be attributed to the presence of kaolinite, while reflections at $4.45 \AA$, $4.29 \AA, 3.35 \AA$ and $2.56 \AA$ were from impurities quartz [25].

A comparison between the diffractograms of the samples after the ionic exchange $(\mathrm{NaCl})$ treatment shows that the peaks remained almost intact, unaffected by the ionic exchange process [26-28].

\subsection{Evaluating the Potential of Na-Enriched Gray Clay in Removing Zinc in a Finite Bath System}

Table 3 illustrates the capacity of Na-enriched gray clay

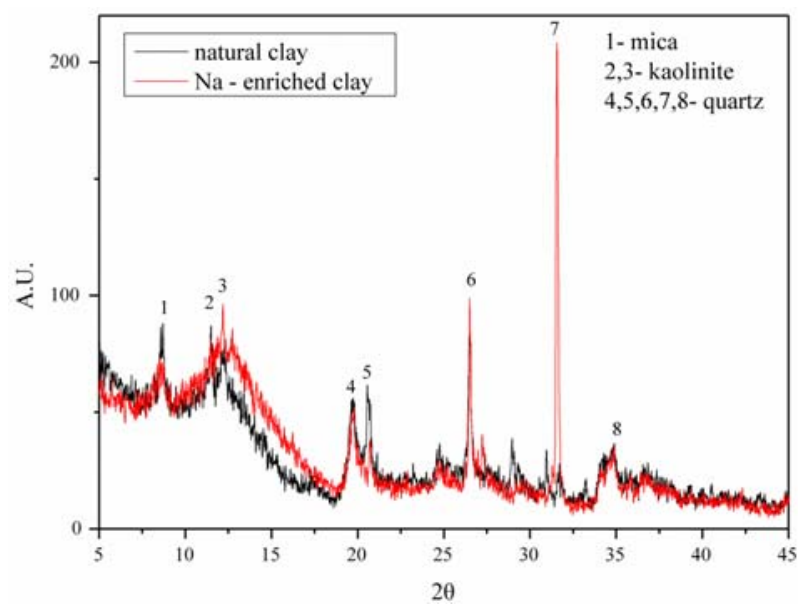

Figure 1. XRD analysis of the natural and Na-enriched clays.

Table 2. Values for the levels chosen.

\begin{tabular}{cc}
\hline Variables & Levels \\
\hline & $(-1)=10$ \\
& $(0)=30$ \\
& $(+1)=50$ \\
& $(-1)=100$ \\
Agitation/rpm & $(0)=150$ \\
& $(+1)=200$ \\
& $(-1)=6$ \\
& $(0)=7$ \\
Solution pH & $(+1)=8$ \\
\hline
\end{tabular}


for removing $\mathrm{Zn}^{2+}$ from synthetic effluents. As stated before, the experimental conditions were based on $2^{3}$ factorial planning. According to results obtained for the total metal ( $\mathrm{Zn})$ removal and the removal capacity of the zinc at equilibrium, Table 3 , the best results were obtained with the experimental conditions 6 and 8, with removal of $99.12 \%$ and $98.53 \%$, respectively. It is reasonable to assume that the dissolution the ion exchange/ adsorption and the precipitation are the mechanism that significantly influence the adsorption characteristics of this clay [33]. According to Kaya and Ören [15], zinc hydroxides are formed at a $\mathrm{pH}$ above 7 and these hydroxides precipitate more readily on the clay surface, thereby increasing the percentage of metal removed. It was also observed that for the removal capacity zinc at equilibrium, i.e. $q_{e q}$ (amount of zinc removed per gram of clay), the best results were obtained in tests of greater concentration. As it can be noticed, the experimental conditions 6 and 8 presented the best results, assuming values equal to 4.37 and $4.34 \mathrm{mg}$ of zinc are removed for every gram of clay, respectively.

\subsection{Adsorption Isotherms}

Table 4 presents the results of the total metal $(\mathrm{Zn})$ removal percentage (Rem \%) by Na-enriched gray clay and its zinc removal capacity at equilibrium which were obtained from experiments performed in a finite bath system.

It is observed that the zinc removal capacity at equilibrium increases for higher values of zinc concentration in the solution, since the higher the concentration, the greater the amount of metal $(\mathrm{Zn})$ in the solution and as

Table 3. 23 Factorial experimental design results.

\begin{tabular}{ccccccc}
\hline test & $\begin{array}{c}\mathrm{C}_{0} \\
(\mathrm{mg} / \mathrm{L})\end{array}$ & $\begin{array}{c}\text { Agit. } \\
(\mathrm{rpm})\end{array}$ & $\mathrm{pH}$ & $\begin{array}{c}\mathrm{Zn} \\
(\mathrm{mg} / \mathrm{L})\end{array}$ & $\%$ Rem & $\begin{array}{c}q_{e q} \\
(\mathrm{mg} / \mathrm{g})\end{array}$ \\
\hline 1 & 10 & 100 & 6.0 & 0.50 & 93.67 & 0.74 \\
2 & 50 & 100 & 6.0 & 4.02 & 90.88 & 4.01 \\
3 & 10 & 200 & 6.0 & 0.55 & 93.04 & 0.73 \\
4 & 50 & 200 & 6.0 & 7.80 & 82.31 & 3.63 \\
5 & 10 & 100 & 8.0 & 0.64 & 91.90 & 0.73 \\
6 & 50 & 100 & 8.0 & 0.39 & 99.12 & 4.37 \\
7 & 10 & 200 & 8.0 & 0.45 & 94.30 & 0.74 \\
8 & 50 & 200 & 8.0 & 0.65 & 98.53 & 4.34 \\
9 & 30 & 150 & 7.0 & 0.50 & 97.92 & 2.35 \\
10 & 30 & 150 & 7.0 & 0.64 & 97.33 & 2.34 \\
11 & 30 & 150 & 7.0 & 0.72 & 97.00 & 2.33 \\
\hline
\end{tabular}

Table 4. Data equilibrium by removing the zinc finite bath (150 rpm, 5 hours).

\begin{tabular}{ccccc}
\hline $\begin{array}{c}\mathrm{C}_{\mathrm{i}} \\
(\mathrm{mg} / \mathrm{L})\end{array}$ & $\begin{array}{c}\mathrm{C}_{\mathrm{R}} \\
(\mathrm{mg} / \mathrm{L})\end{array}$ & $\begin{array}{c}C_{e q} \\
(\mathrm{mg} / \mathrm{L})\end{array}$ & $\begin{array}{c}\% \text { Rem. } \\
\text { (zinc) }\end{array}$ & $\begin{array}{c}q_{e q} \\
(\mathrm{mg} / \mathrm{g})\end{array}$ \\
\hline 10.0 & 7.0 & 0.34 & 95.14 & 0.66 \\
30.0 & 22.2 & 1.21 & 94.55 & 2.09 \\
50.0 & 40.8 & 3.23 & 92.08 & 3.75 \\
70.0 & 61.3 & 6.55 & 89.31 & 7.94 \\
100.0 & 86.0 & 9 & 89.53 & 7.70 \\
\hline
\end{tabular}

$\mathrm{C}_{\mathrm{i}}$ : initial concentration; $\mathrm{C}_{\mathrm{R}}$ : real initial concentration; $C_{e q}:$ equilibrium concentration; $q_{e q}$ : removal capacity.

the removal capacity represents the amount of metal removed per gram of clay, there will be more metal in the more concentrated solutions. When the initial solution concentration, is low, the ratio between the number of ions and the number adsorptive sites available is small; as the adsorption rate depends on the initial concentration. Therefore, as the concentration de ions increases, the adsorption capacity increases. At high ion concentrations, each unit mass of adsorbent is subjected to a larger number of ions, which gradually fill up the sites. Thus, an increase in zinc removal capacity at equilibrium $\left(q_{e q}\right)$ and a reduction in the total metal $(\mathrm{Zn})$ removal percentage are observed.

Figure 2 shows the removal isotherm to Na-enriched gray clay in a finite bath system, whose experimental data were obtained based on the following process conditions: agitation of $150 \mathrm{rpm}, \mathrm{pH}$ controlled at 8 and temperature of $27^{\circ} \mathrm{C}$ for 5 hours.

The adsorption equilibrium be generally described by an isotherm presenting model parameters which reflect the surface properties and affinity of the adsorbent, at predetermined temperature and $\mathrm{pH}$ values. The isotherms can be successfully adjusted to mathematical models, especially those of Langmuir (Equation (4)) and Freundlich (Equation (6)).

\subsubsection{Langmuir Isotherm}

Langmuir isotherm models the single coating layer on adsorption surface. This model supposes that the adsorption takes place at a specific adsorption surface. The attraction between molecules decreases as getting further from the adsorption surface [29]. Langmuir isotherm can be expressed formulas as follows:

$$
q_{e q}=\frac{q_{\max } C_{e q}}{k+C_{e q}}
$$

where $q_{e q}$ is the amount of adsorbed heavy metal per unit clay mass $(\mathrm{mg} / \mathrm{g}), V_{m}$ is the monolayer capacity, $k$ is the equilibrium constant and $C_{e q}$ is the equilibrium concentration of the solution $(\mathrm{mg} / \mathrm{L})$. 


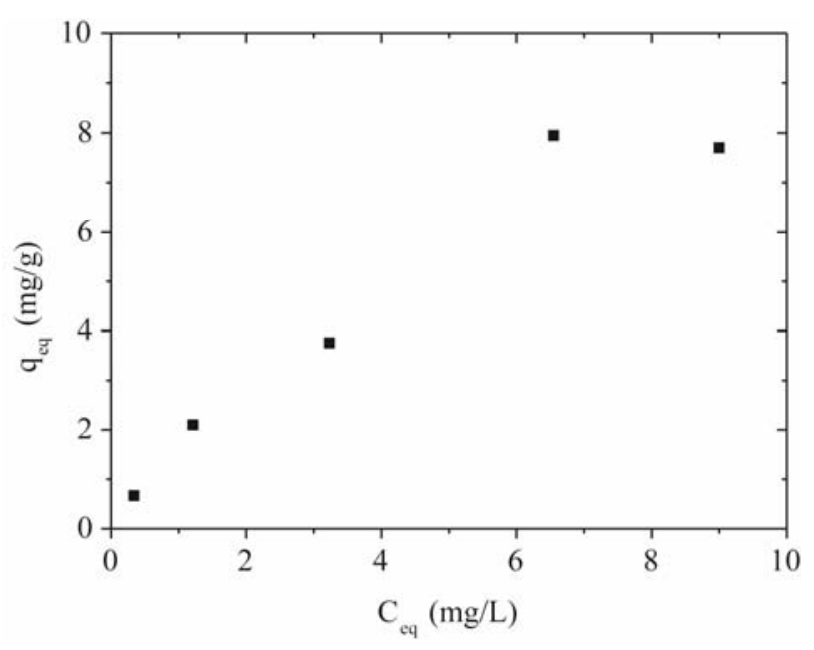

Figure 2. Zinc adsorption isotherm on Na-enriched clay.

The experimental data were fitted to the model Langmiur. So Equation (4) can be expressed in the linearized way as follows.

$$
\frac{1}{q_{e q}}=\frac{k}{q_{\max } C_{e q}}+\frac{1}{q_{\max }}
$$

where, $q_{\max }=$ maximum removal.

\subsubsection{Freundlich Isotherm}

Freundlich isotherm is used to evaluate the adsorption on heterogeneous surface. This isotherm can be expressed by the following equation:

$$
q_{e q}=k_{d} C_{e q}^{\frac{1}{n}} .
$$

When the linearization is performed, Freundlich model can be expressed as:

$$
\log q_{e q}=\log k_{F}+\frac{1}{n} \log C_{e q}
$$

Linearizations of the zinc adsorption isotherm for Naenriched gray clay: (A) Langmuir model and (B) Freundlich model are represented in Figure 3.

It is observed that the adsorption data of zinc for Na-enriched gray clay fit better in the linearized Langmuir model, as the correlation coefficients show. The Table 5 resumes the values of the parameters obtained from the linearized equations.

Figure 4 shows the adjustments of the Langmuir and Freundlich models to the experimental data obtained for Na-enriched gray clay. In addition to the experimental data, the linearized form of Langmuir and Freundlich isotherm using Equations (5) and (6) for zinc ion removal by clay can be seen in Figure 4 .

The comparison of the experimental values with the values of removal capacity zinc at equilibrium $q_{e q}$ ob

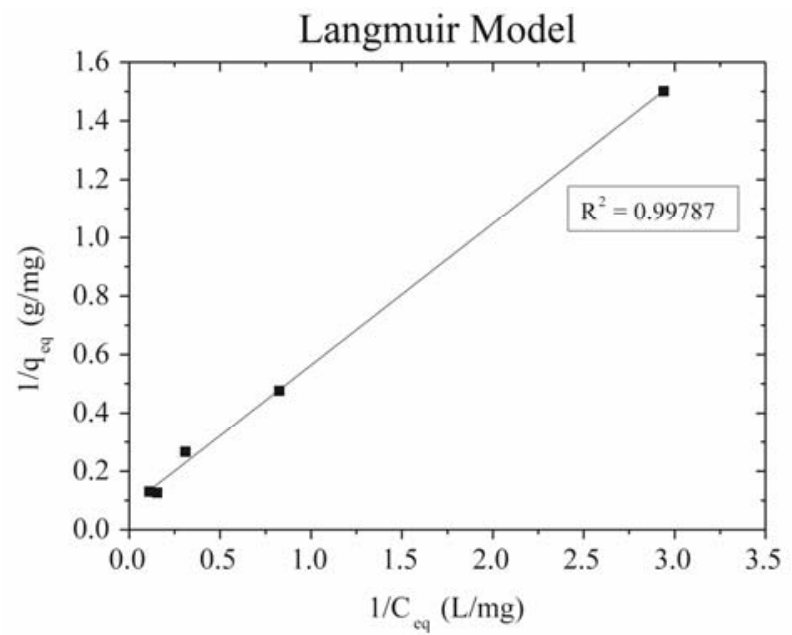

(a)

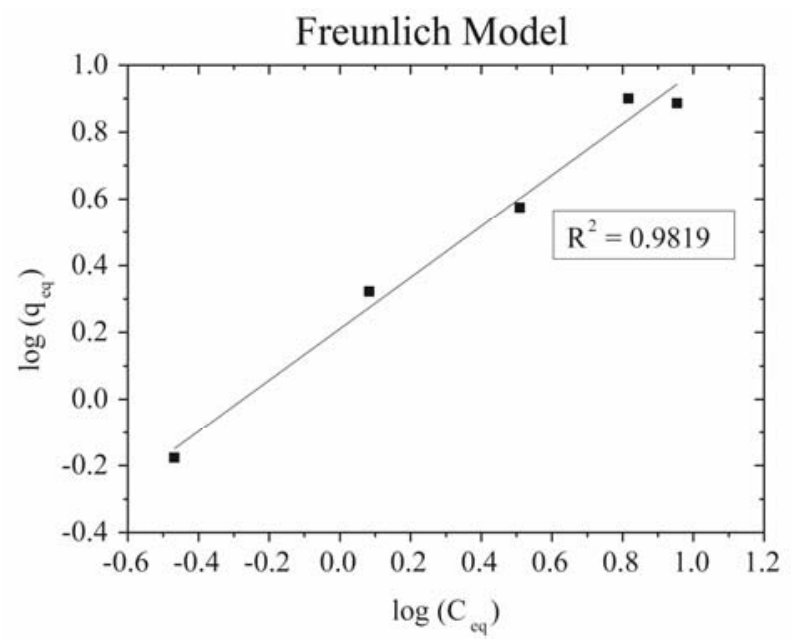

(b)

Figure 3. Plot of adsorption of zinc isotherm on Na-enriched clay. (a) Langmuir model; (b) Freundlich model.

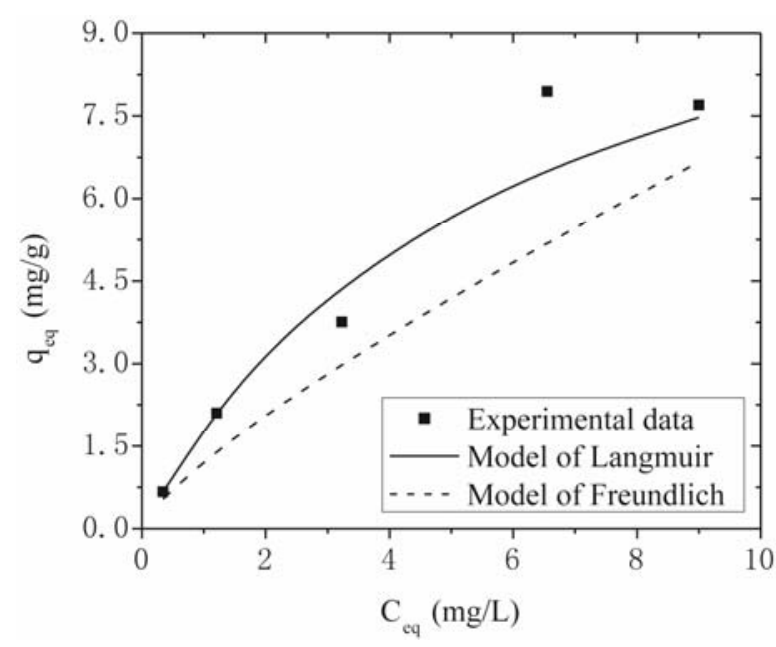

Figure 4. Adjustment of the Langmuir and Freundlich models to the experimental data obtained for Na-enriched clay. 
Table 5. Parameters obtained for the linearized Langmuir and Freundlich equations.

\begin{tabular}{cc}
\hline Langmuir & Freundlich \\
& $k=1.23$ \\
$q_{m}=12.5$ & $n=1.30$ \\
$K_{d}=6.05$ & \\
\hline
\end{tabular}

tained by both models is shown in Figure 4. As it can be seen, Langmuir isotherms usually fitted better with the experimental date rather than Freundlich isotherms. This behavior agrees very well with other studies presented in the open literature regarding to experimental results of heavy metals removal $[14,29]$.

Mellah and Chegrouche [1] used natural bentonite for elimination of $\mathrm{Zn}$ (II) from aqueous solution. The process was favoured by high values of initial of initial Zn (II) concentration and reduced particle size of clay adsorbent. It was also observed that process performance was strongly dependent on the agitation speed.

After $\cong 15 \mathrm{~min}$, the amount of $\mathrm{Zn}$ (II) adsorbed was higher for 200 than $500 \mathrm{rpm}$. It was likely that more particles were broken at $500 \mathrm{rpm}$ or/and the suspension was not homogeneous at $500 \mathrm{rpm}$. In the temperature range of 293 to $353 \mathrm{~K}$, Freundlich adsorption capacity varied 2.3 to $8.4 \mathrm{~L}^{-} \mathrm{g}^{-1}$ and Langmuir monolayer adsorption capacity varied between 25.8 to $52.9 \mathrm{mg} \cdot \mathrm{g}^{-1}$ (Table 5).

The values obtained for the Langmuir $(k=1.23$ and $n$ $=1.30)$ and Freundlich $\left(q_{m}=12.5\right.$ and $\left.K_{d}=6.05\right)$ are significantly different from the one observed by Mellah and Chegrouche [1], Langmuir $\left(K_{f}=8.4\right.$ and $\left.1 / \mathrm{n}=0.20\right)$ and Freundlich $\left(q_{m}=52.9\right.$ and $\left.\mathrm{b}=0.01\right)$, probably due to different characteristic of the clays used in both studies. For this reason, a direct comparison has to be avoided.

As the adjustment by the model of the Langmuir isotherm was more representative, the process of removing zinc, in a finite bath system by Na-enriched gray clay can be given by Equation (8).

$$
q_{e q}=\frac{12.5 \times C_{e q}}{6.05+C_{e q}}
$$

For practical reason, the affinity between $\mathrm{Zn}^{+2}$ ions and Na-enriched gray clay can be predicted using Langmuir dimensionless separation factor given by the following equation: [30-32].

$$
R_{L}=\frac{1}{1+k_{d} C_{0}}
$$

where: $C_{0}$ is the initial concentration $(\mathrm{mg} / \mathrm{L}) ; k_{d}$ is the constant of affinity $(\mathrm{L} / \mathrm{mg})$.

In this case, the parameter $R_{L}$ indicates the form of the isotherm in accordance with the following ratios:

$\begin{array}{cl}\text { Value of } R_{\mathrm{L}} & \text { Types of isotherms } \\ R_{L}>1 & \text { Not favorable } \\ R_{L}=1 & \text { Linear }\end{array}$

$$
\begin{array}{ll}
0<R_{L}<1 & \text { Favorable } \\
R_{L}=0 & \text { Irreversible }
\end{array}
$$

The values calculated for $R_{L}$ (Equation (9)) determined by using the Langmuir constant obtained by the nonlinear method versus the initial zinc concentration is shown the Table 6. According values, it is verified that under the process conditions zinc sorption is considered favorable $\left(0<R_{L}<1\right)$.

\subsection{Adsorption Kinetics}

Adsorption kinetics is used in order to explain the adsorption mechanism and adsorption characteristics.

The representation of the kinetics of removing zinc by Na-enriched gray clay is presented in Figure 5.

The adsorption of zinc ions into clay pores is found to occur rapidly at the first moments of the process, remaining virtually at equilibrium over time. It can be seen from Figure 5 that there was a sharp drop in the concentration of zinc in the solution, reaching a minimum of $2.45 \mathrm{mg} / \mathrm{L}$ of zinc in 2 minutes. It is possible to verify that equilibrium is reached after 40 minutes.

Adsorption of heavy metals at the oxide/water interface can be described as the surface complexation [32]. The uptake of heavy metals by clay minerals is obviously

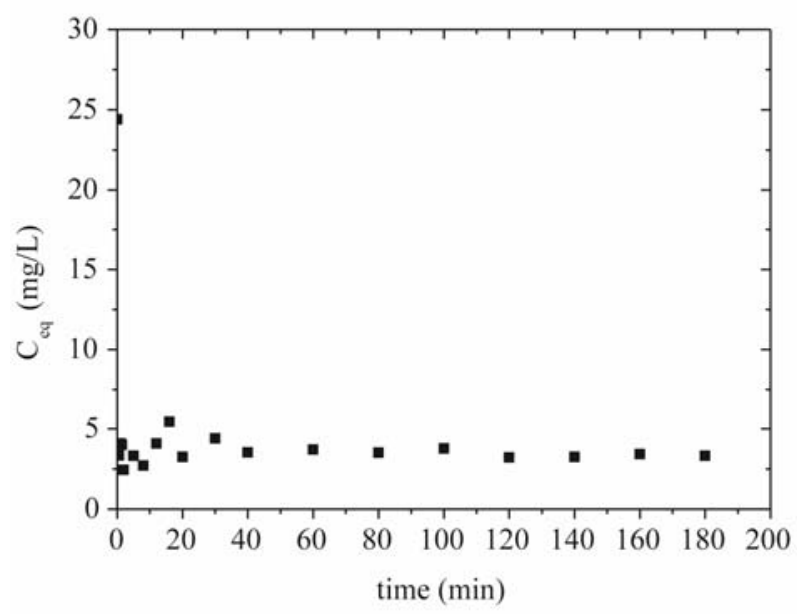

Figure 5. Adsorption kinetics of zinc on Na-enriched clay.

Table 6. Values of Langmuir's adimensional separation factor.

\begin{tabular}{ccc}
\hline $\begin{array}{c}\text { Theoretical Initial } \\
\text { Concentration }(\mathrm{mg} / \mathrm{L})\end{array}$ & $\begin{array}{c}\text { Real Initial } \\
\text { Concentration } \\
(\mathrm{mg} / \mathrm{L})\end{array}$ & $R_{L}$ \\
\hline 10.0 & 7.0 & 0.023 \\
30.0 & 22.2 & 0.007 \\
50.0 & 40.8 & 0.004 \\
70.0 & 61.3 & 0.003 \\
100.0 & 86.0 & 0.002 \\
\hline
\end{tabular}


more complicated. The chemical nature of metal clay interaction changes with increasing $\mathrm{pH}$ : at low $\mathrm{pH}$ values cation exchange is dominating process [34], whereas at high $\mathrm{pH}$ values, the uptake of heavy metal ions is accompanied by release of hydrogen ions, and seems to be more specific than the uptake at low $\mathrm{pH}$ values. Thus, the classical ion exchange model does not cover the whole range of adsorption phenomena and a part of heavy metal adsorption occurs at sites created by displacement of protons from surface hydroxyls (i.e. surface complexation) [35].

In the case of the $\mathrm{Na}$-enriched gray clay, the ionisable groups of the layers of the clay constitute the sites of adsorption. For this reason, the $\mathrm{Zn}^{2+}$ ions can be adsorbed on $\mathrm{Mg}(\mathrm{OH})_{2}, \mathrm{SiOH}, \mathrm{Al}(\mathrm{OH})$, which can be regarded as the sites of adsorption. In addition, the silanol groups of the side of the clay layers are transformed in $\mathrm{SiO}-\mathrm{Na}^{+}$ form and the adsorption of these silanol sites is not accompanied by $\mathrm{H}^{+}$.

\section{Kinetic Model}

Equation (10) represents the kinetics model employed for interpretation of the clay-metal interactions. Based on the pseudo-second order model proposed by Ho and Mackay $[36,37]$, it was possible to investigate the mechanism of ad- sorption kinetics, and therefore to predict the behavior of the process by comparing the experimental results with those obtained by the model based on the adsorption ki- netics between zinc and $\mathrm{Na}$-enriched gray clay in a finite bath system.

$$
\frac{t}{q_{t}}=\frac{1}{k q_{e q}^{2}}+\frac{1}{q_{e q}} t
$$

where: $q_{e q}$ : is the amount of $\mathrm{Zn}$ adsorbed at the equilibrium $(\mathrm{mg} / \mathrm{g}) ; q_{t}$ : is the amount of $\mathrm{Zn}$ adsorbed at any given time $(\mathrm{mg} / \mathrm{g}) ; k$ : is the constant of second order velocity $(\mathrm{g} \cdot \mathrm{min} / \mathrm{mg}) ; t$ : is the time $(\mathrm{min})$ and $k q_{e q}^{2}$ corresponds to the initial adsorption rate when $\mathrm{t} \rightarrow 0$.

Pseudo-second order kinetics was also applied for experimental data of zinc adsorption. The adsorption kinetic was adjusted with the second-order kinetics models (Figure 6). The $t / q_{t}$ versus $t$ is graph provides a straight line allowing obtaining $q_{e q}$ and $k$.

Figure 6 shows the good linearization of the model proposed by Ho and Mackay [36] presenting $R^{2}=0.9998$. It means that the proposed model adjusts the experimental data and, therefore, the kinetics of zinc ion adsorption on Na-enriched gray clay follows the pseudo-second order model.

The linear correlation coefficient and second-order constant, as well as the removal capacity zinc at equilibrium obtained in Figure 6 are shown in Table 7.

The second-order behavior indicates that process performance is essentially controlled by the diffusion of zinc

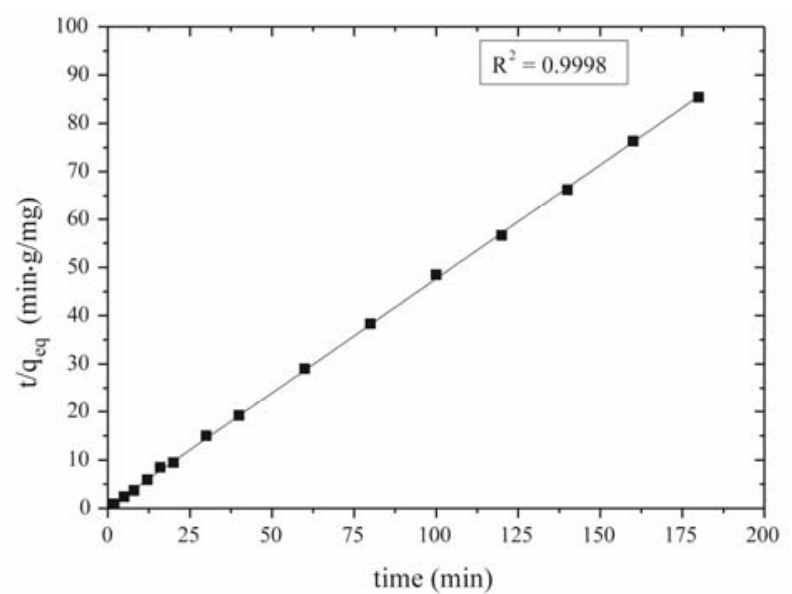

Figure 6. Curve of $t / q_{e q}$ versus time to verify the kinetic model for Na-enriched clay.

Table 7. Kinetic parameters of the pseudo-second order model equation for adsorption of zinc.

\begin{tabular}{ccc}
\hline$k\left(\mathrm{~g} \cdot \mathrm{mg}^{-1} / \mathrm{min}\right)$ & $q_{e q}(\mathrm{mg} / \mathrm{g})$ & $R^{2}$ \\
\hline 1.13 & 2.10 & 0.9998 \\
\hline
\end{tabular}

species into pores, which clearly exemplify that secondorder kinetics models can be successfully used in order to describe interactions that take place during zinc adsorption into the clay pores.

\section{Conclusions}

In this study, removal of $\mathrm{Zn}^{2+}$ is investigated using Na-enriched gray clay.

Total metal $(\mathrm{Zn})$ removal percentage as high as 99.12 $\%$ could be obtained, when the initial solution $(\mathrm{Zn})$ concentration is used on its higher level $(50 \mathrm{mg} / \mathrm{L})$ and the degree of agitation is at the lower level $(100 \mathrm{rpm})$. It was also observed that, for the absolute capacity of removal $\left(q_{\text {eq }}\right)$, the best results were obtained in tests performed with higher $(50 \mathrm{mg} / \mathrm{L})$ concentration, the best result being a total of $4.37 \mathrm{mg}$ of $\mathrm{Zn}$ removed for every gram of clay.

The adsorption isotherms were better represented by the Langmuir model for the process.

Using the study of the kinetics of removing zinc, in a finite bath system, by Na-enriched gray clay, it was verified that the equilibrium time is reached after the elapse of 40 minutes and the percentage removal of zinc was $86.39 \%$.

The second-order kinetic model represented well the mechanism of interaction involved during zinc adsorption into the pores of the $\mathrm{Na}$-enriched gray clay.

The value of the velocity constant obtained by the model was $1.13(\mathrm{~g} \cdot \mathrm{min} / \mathrm{mg})$, that of the amount of $\mathrm{Zn}$ adsorbed was $2.10(\mathrm{mg} / \mathrm{g})$ and the adjustment for the corre- 
lation coefficient of the model was 0.9998 .

The process for removing zinc using Na-enriched gray clay proved to be adequate and highly efficient.

\section{Acknowledgements}

The authors thank Süd-Chemie do Brasil Ltd for donating the clay and $\mathrm{CNPq}$ (Brazilian Research Council) for the financial support to carry out this study.

\section{REFERENCES}

[1] A. Mellah and S. Chegrouche, "The Removal of Zinc from Aqueous Solutions by Natural Bentonite," Water Research, Vol. 31, No. 3, 1997, pp. 621-629. doi:10.1016/S0043-1354(96)00294-1

[2] F. Fu and Q. Wang, "Removal of Heavy Metal Ions from Wastewaters: A Review," Journal of Environmental Management, Vol. 92, No. 3, 2011, pp. 407-418. doi:10.1016/i.jenvman.2010.11.011

[3] P. N. Cheremisinoff, "Handbook of Water and Wastewater Treatment Technology," Marcel Dekker Inc., New York, 1995.

[4] S. Veli and T. Öztürk, "Kinetic Modeling of Adsorption of Reactive Azo Dye on Powdered Activated Carbon and Pumice," Fresenius Environmental Bulletin, Vol. 14, No. 3, 2005, pp. 212-218.

[5] S. Babel and T. A. Kurniawan, "Low-Cost Adsorbents for Heavy Metal Uptake from Contaminated Water," Journal of Hazardous Materials, Vol. 97, No. 1-3, 2003, pp. 219243.

[6] G. McKay, H. S. Blair and A. Findon, "Equilibrium Studies for the Sorption of Metal-Ions onto Chitosan," Indian Journal of Chemistry A, Vol. 28, No. 5, 1989, pp. 356360.

[7] A. Saeed, M. Iqbal and W. Akhtar, "Removal and Recovery of Lead(II) from Single and Multimetal $(\mathrm{Cd}, \mathrm{Cu}, \mathrm{Ni}$, $\mathrm{Zn}$ ) Solutions by Crop Milling Waste (black gram husk)," Journal of Hazardous Materials, Vol. 117, No. 1, 2005, pp. $65-73$.

[8] N. Meunier, J. Laroulandie, J. F. Blais and R. D. Tyagi, "Cacao Shells for Heavy Metal Removal from Acidic Solutions," Bioresource Technology, Vol. 90, No. 3, 2003, pp. 255-263. doi:10.1016/S0960-8524(03)00129-9

[9] K. A. Tanabe, Jr. and M. Boudart, "Catalysis-Science and Technology. Solid Acid and Base Catalysis," Springer-Verlag, New York, 1981, p. 231.

[10] Van Olphen, H., “An Introduction to Clay Colloid cHemistry," Wiley Intersciene, 1977, p. 187.

[11] T. A. Kurniavan, G. Y. S. Chan, W. H. Lo and S. Babel, "Comparisons of Low-Cost Adsorbents for Treating Wastewaters Laden with Heavy Metals," Science of the Total Environment, Vol. 366, No. 2-3, 2006, pp. 409-426. doi:10.1016/j.scitotenv.2005.10.001

[12] R. Naseem and S. S. Tahir, "Removal of $\mathrm{Pb}$ (II) from Aqueous/Acidic Solutions by Using Bentonite as an Adsorbent," Water Research, Vol. 35, No. 16, 2001, pp. 3982-3986. doi:10.1016/S0043-1354(01)00130-0
[13] E. Eren, "Removal of copper ions by modified Unye clay, Turkey," Journal of Hazardous Materials, Vol. 159, No. 2-3, 2008, pp. 235-244. doi:10.1016/j.jhazmat.2008.02.035

[14] F. Barbier, G. Duc and M. Petit-Ramel, "Adsorption of Lead and Cadmium Ions from Aqueous Solution to the Montmorillonite: Water Interface," Colloids and Surfaces A: Physicochemical and Engineering Aspects, Vol. 166, No. 1-3, 2000, pp. 153-159. doi:10.1016/S0927-7757(99)00501-4

[15] A. Kaya and A. H. Ören, "Adsorption of Zinc From Aqueous Solutions to Bentonite," Journal of Hazardous Materials, Vol. 125, No. 1-3, 2005, pp. 183-189.

[16] K.G. Bhattacharyya and S. S. Gupta, "Adsorption of a Few Heavy Metals on Natural and Modified Kaolinite and Montmorillonite: A Review," Advances in Colloid and Interface Science, Vol. 140, No. 2, 2008, pp. 114131.

[17] K. G. Bhattacharyya and S. S. Gupta, "Adsorptive Accumulation of $\mathrm{Cd}$ (II), $\mathrm{Co}$ (II), $\mathrm{Cu}$ (II), $\mathrm{Pb}$ (II), and $\mathrm{Ni}$ (II) from Water on Montmorillonite: Influence of Acid Activation," Journal of Colloid and Interface Science, Vol. 310, No. 2, 2007, pp. 411-424. doi:10.1016/j.jcis.2007.01.080

[18] P. A. O’Day, G. A. Parks and G. E. Brown Jr., "Molecular Structure and Binding Sites of Co (II) Surface Complexes on Kaolinite from X-ray Adsorption Spectroscopy," Clays and Clay Minerals, Vol. 42, No. 3,1994, pp. 337- 355. doi:10.1346/CCMN.1994.0420312

[19] M. B. McBride, "Copper (II) Interactions with Kaolinite: Factors Controlling Adsorption," Clays and Clay Minerals, Vol. 26, No. 2, 1978, pp. 101-106. doi:10.1346/CCMN.1978.0260204

[20] V. Chantawong, N. W. Harvey and V. N. Bashkin, "Comparison of Heavy Metal Adsorptions by Thai Kaolin and Ballclay Water," Air \& Soil Pollution, Vol. 148, No. 1-4, 2003, pp. 111-125. doi:10.1023/A:1025401927023

[21] G. Suraj, C. S. P. Iyer and M. Lalithambika, “Adsorption of Cadmium and Copper by Modified Kaolinites," Applied Clay Science, Vol. 13, No. 4, 1998, pp. 293-306. doi:10.1016/S0169-1317(98)00043-X

[22] S. M. Dal Bosco, R. S. Jimenez, C. Vignado, J. Fontana, B. Geraldo, F. C. A. Figueiredo, D. Mandelli and W.A. Carvalho, "Removal of Mn (II) and Cd (II) from Wastewater by Natural and Modified Clays," Adsorption, Vol. 12, No. 2, 2006, pp. 133-146. doi:10.1007/s10450-006-0375-1

[23] U. M. Saha, K. Iwasaki and K. Sakurai, "Desorption Behavior of $\mathrm{Cd}, \mathrm{Zn}$ and $\mathrm{Pb}$ Sorbed on Hydroxyaluminumand Hydroxyaluminosilicate-Montmorillonite Complexes," Clays and Clay Minerals, Vol. 51, No. 5, 2003, pp. 481-492. doi:10.1346/CCMN.2003.0510502

[24] Z. E. Grim, "Clay Mineralogy," 2nd Edition, McGramHill Book, New York, 1968.

[25] P. Souza Santos, "Ciência e Tecnologia das Argilas," 2nd Edition, Vol. 1, Edgard Blücher Ltd., São Paulo, 1992.

[26] J. B. Dixon, "Roles of Clays in Soils," Applied Clay Science, Vol. 5, No. 5-6, 1991, pp. 489-503. 
doi:10.1016/0169-1317(91)90019-6

[27] E. Manias, A. Touny, L. Wu, K. Strawhecker, B. Lu and T. C. Chung, "Polypropylene/Montmorillonite Nanocomposites. Review of the Synthetic Routes and Materials Properties," Chemical Materials, Vol. 13, No. 10, 2001, pp. 3516-3523.

doi: $10.1021 / \mathrm{cm} 0110627$

[28] I. J. Chin, T. Thurn-Albrecht, H. C. Kim, T. P. Russell and J. Wang, "On Exfoliation of Montmorillonite in Epoxy," Polymer, Vol. 42, No. 13, 2001, pp. 5947-5952. doi:10.1016/S0032-3861(00)00898-3

[29] N. Ünlü and M. Ersoz, "Adsorption Characteristics of Heavy Metal Ions onto a Low Cost Biopolymeric Sorbent from Aqueous Solutions," Journal of Hazardous Materials, Vol. 136, No. 2, 2006, pp. 272-280.

[30] A. S. Sheta, A. M. Falatah, M. S. Al-Sewailem, E. M Khaled and A. S. H. Sallam "Sorption Characteristics of Zinc and Iron by Natural Zeolite and Bentonite," Microporous and Mesoporous Materials, Vol. 61, No. 1-3, 2003, pp. 127-136. doi:10.1016/S1387-1811(03)00360-3

[31] A. Benhammoua, A. Yaacoubia, L. Niboub and B. Tanoutia, "Adsorption of Metal Ions onto Moroccan Stevensite: Kinetic and Isotherm Studies," Journal of Colloid and Interface Science, Vol. 282, No. 2, 2005, pp. 320-326. doi:10.1016/j.jcis.2004.08.168
[32] N. Öztürk and D. Kavak, "Removal from Aqueous Solutions by Adsorption on Waste Sepiolite and Activated Waste Sepiolite Using Full Factorial Design," Adsorption, Vol. 10, No. 3, 2004, pp. 245-257. doi:10.1023/B:ADSO.0000046361.62180.c6

[33] F. Bergaya, B. K. G. Theng and G. Lagaly, "Handbook of Clay Science," Elsevier, Amsterdam, 2006.

[34] P. W. Schindler and W. Stumm, "Aquatic Surface Chemistry," Wiley, New York, 1987.

[35] M. Stadler and P. W. Chindler, "The Effect OF Dissolved Ligands upon the Sorption of $\mathrm{Cu}(\mathrm{II})$ By Ca-Montmorillonite," Clays and Clay Minerals, Vol. 41, No. 6, 1993, p. 680. doi:10.1346/CCMN.1993.0410606

[36] Y. S. Ho and G. Mckay, "Kinetic Models for the Sorption of Dye from Aqueous Solution by Wood," Protection, Vol. 76, No. 2, 1998, pp. 183-191.

[37] M. G. A. Vieiraa, A. F. Almeida Netoa, M. L. Gimenesb and M. G. C. Da Silva, "Removal of Nickel on Bofe Bentonite Calcined Clay in Porous Bed," Journal of Hazardous Materials, Vol. 176, No. 1-3, 2010, pp. 109-118. doi:10.1016/j.jhazmat.2009.10.128 